\title{
Mental Health and Psychosocial Functioning Over the Lifespan of German Patients Undergoing Cardiac Catheterization for Coronary Artery Disease
}

\author{
Anja Schaich ${ }^{1 *}$, Anna L. Westermair ${ }^{1}$, Matthias Munz ${ }^{2}$, Stefan Nitsche ${ }^{1,2,3,4}$, \\ Bastian Willenborg ${ }^{1}$, Christina Willenborg ${ }^{2,3,4}$, Heribert Schunkert ${ }^{5,6}$, Jeanette Erdmann ${ }^{2,3,4}$ \\ and Ulrich Schweiger ${ }^{1}$ \\ ${ }^{1}$ Department of Psychiatry and Psychotherapy, University of Lübeck, Lübeck, Germany, ${ }^{2}$ Institute for Cardiogenetics, \\ University of Lübeck, Lübeck, Germany, ${ }^{3}$ University Heart Center, University of Lübeck, Lübeck, Germany, ${ }^{4}$ DZHK, German \\ Centre for Cardiovascular Research, Partner site Hamburg, Kiel, Lübeck, Germany, ${ }^{5}$ Deutsches Herzzentrum München \\ (German Heart Center Munich), Fakultät für Medizin, Technische Universität München, Munich, Germany, ${ }^{6}$ Deutsches \\ Zentrum für Herz-Kreislaufforschung e.V., Partner site Munich, Munich, Germany
}

OPEN ACCESS

Edited by:

Michael Noll-Hussong, Universitätsklinikum des Saarlandes,

Germany

Reviewed by:

Andreas Dinkel,

Technische Universität München,

Germany

Ailin Barseghian,

University of California, Irvine,

United States

*Correspondence:

Anja Schaich

anja.schaich@uksh.de

Specialty section:

This article was submitted to

Psychosomatic Medicine

a section of the journal

Frontiers in Psychiatry

Received: 12 March 2018

Accepted: 05 July 2018

Published: 27 July 2018

Citation:

Schaich A, Westermair AL, Munz M, Nitsche $S$, Willenborg B, Willenborg $C$,

Schunkert H, Erdmann $J$ and Schweiger U (2018) Mental Health and Psychosocial Functioning Over

the Lifespan of German Patients Undergoing Cardiac Catheterization

for Coronary Artery Disease.

Front. Psychiatry 9:338.

doi: 10.3389/fpsyt.2018.00338
Background: Psychological problems are common in patients with coronary artery disease (CAD) and are associated with poor outcome. However, data on the prevalence of distinct mental disorders and their relevance to patients' functioning in daily life are scarce.

Method: In this retrospective study, a total of 514 German patients with CAD as diagnosed by cardiac catheterization were assessed using the Mini International Neuropsychiatric Interview 5.0.0 (M.I.N.I.) and psychosocial functioning was evaluated using the Global Assessment of Functioning (GAF) scale.

Results: Twenty-nine percent of the participants suffered from at least one mental disorder after the onset of their CAD (mean time since onset $=10.86$ years, $S D=8.15$ ). In comparison to the period before onset of $C A D$, elevated prevalence rates were found for severe depressive episodes, agoraphobia, dysthymia, panic disorder, and hypochondria. Predictors of mental disorders after the onset of CAD were female gender, younger age at onset of CAD as well as mental disorders and low GAF scores before onset. GAF scores decreased after the onset of $C A D$, recovered only partially, and were influenced by mental disorders before onset in women but not in men.

Conclusions: Mental disorders - especially depression and agoraphobia-are frequent in patients with $C A D$, with women, patients with a younger age at onset of CAD and patients with any history of mental disorders especially at risk. Regardless of whether patients meet any specific diagnostic criteria, psychosocial functioning is markedly impaired after the onset of CAD, underscoring the need for specific mental health programs for this patient population. Future research, ideally using a prospective design, is necessary to confirm these findings and to further the knowledge of prevalence rates of mental disorders and of modifiable risk factors for the development of mental disorders in patients with CAD.

Keywords: coronary artery disease, psychosocial functioning, mental disorders, mental health, prevalence rates 


\section{INTRODUCTION}

Coronary artery disease (CAD) is a highly prevalent and impairing disease, known to be the most common cause of death in industrialized countries $(1,2)$. Prevalence rates of CAD are estimated at $4.8 \%$ (12-month-prevalence) (3) and 8.2\% (lifetime prevalence) (4) in Germany and at $6.2 \%$ (12-month prevalence) (5) and $7.3 \%$ (6) (lifetime prevalence) in the US.

Several studies indicated that mental health problems are common in patients with CAD. Depressive symptoms in this patient population have been found in 8.2 to $35.7 \%$ of men and in 10.3 to $62.5 \%$ of women in European countries (7), and a review identified clinical significant symptoms of depression in 31 to $40 \%$ of patients with $\mathrm{CAD}$ and prevalence rates between 15 and $20 \%$ for major depressive disorder (8). Anxiety symptoms were found in 12.0 to $41.8 \%$ of men and 21.5 to $63.7 \%$ of women with CAD (7). Other studies found prevalence rates of anxiety disorders between 7 and 20\%, with generalized anxiety disorder being most prevalent $(9,10)$. Research on other mental health problems in patients with CAD are scarcer, with some small studies indicating an increase in prevalence rates of e.g., binge eating disorder $(11,12)$. Depressive symptoms and anxiety seem to be associated with higher rehabilitation attrition rates (13) as well as worse adherence to medication $(14,15)$ and advised lifestyle changes (16). There is also substantial evidence, that depressive symptoms and anxiety in patients with $\mathrm{CAD}$ are associated with poorer prognosis, indicating a higher risk for mortality and morbidity (17-22). Comorbid mental health problems, especially depressive symptoms and anxiety are also associated with higher medical costs due to frequent hospital stays, specialist and emergency ward visits and social costs $(23,24)$. For these reasons, the development of adequate treatment programs for this patient group seems to be a necessary and important field. However, current data on the treatment of mental health problems in patients with $\mathrm{CAD}$ are inconsistent, two meta-analyses and one Cochrane review found some evidence for the effectiveness of psychological and psychiatric interventions in the reduction of depressive symptoms and anxiety but none or only small evidence for the reduction of death rates or cardiological events in patients with CAD (25-27). To date, there is little data on prevalence rates of mental disorders in German patients with CAD and little data on the association between mental health and psychosocial functioning in this patient group. The aim of the present study was to provide prevalence rates of mental disorders and psychosocial functioning over time in a large sample of German CAD patients.

\section{MATERIALS AND METHODS}

\section{Participants}

One thousand one hundred eighty-two patients with CAD (303 female, 879 male, age $M=62.19, S D=11.13$ ), admitted to the university hospital of Lübeck, Germany, for cardiac catheterization between February 2004 and December 2012, gave fully informed consent at the time of admission to have their data used for research purposes and to be contacted for further research purposes. Five hundred fourteen patients agreed to participate in the telephone survey when contacted by phone several years later $(\mathrm{Md} .=5$ years, IQR $=3)$, between March 2013 and January 2015. The exclusion criteria were lack of informed consent, inability to participate in a telephone survey (due to cognitive deficits, hearing impairment, aphasia or insufficient language skills) and exclusion of CAD during cardiac catheterization.

\section{Assessment of Physical Health}

Upon admission to the hospital, participants were interviewed on cardiovascular risk factors such as arterial hypertension, diabetes, hypercholesterolemia, and smoking. Also, their BMI was determined. Cardiac function was quantified as left ventricular ejection fraction by echocardiography. All participants underwent cardiac catheterization.

\section{Assessment of Mental Health Mental Disorders}

During the telephone survey, the Mini International Neuropsychiatric Interview (M.I.N.I. 5.0.0) was used $(28,29)$. The M.I.N.I. is a short, structured diagnostic interview for DSM-IV (30) and ICD-10 (31) mental disorders and has good psychometric qualities. Compared to the Composite International Diagnostic Interview (CIDI) kappa coefficient, sensitivity and specificity are good or very good for most diagnosis and inter-rater and test-retest reliability are good (32). The M.I.N.I. has been administered via telephone in previous studies (33-35). This study focused on more severe mental disorders, mild forms of mental disorders (e.g., depressive episodes with less than 7 criteria met, specific phobias, adjustment disorders) were not included in the analysis. The M.I.N.I. was administered regarding the periods before and after the onset of $\mathrm{CAD}$ as well as regarding the time of the interview. The onset of the CAD was defined as the year in which one of the following criteria was first met: (a) CAD symptoms (e.g., chest pain, chest tightness) not otherwise explicable, (b) cardiac catheterization showing $\mathrm{CAD}$, or (c) diagnosis of a myocardial infarction. Participants were divided into four groups: continuously healthy (no mental disorder before or after onset of CAD), remitted (mental disorder before but not after onset of CAD), newly ill (mental disorder after but not before onset of CAD) and continuously ill (mental disorder before and after onset of CAD).

\section{Psychosocial Functioning}

Psychosocial functioning was assessed using the Global Assessment of Functioning (GAF), which has been shown to possess good psychometric properties (36). According to the DSM-IV, this standard method of judgment of a patient's level of psychological, social, and occupational functioning is rated on a scale from 1 to 100 and divided into 10-point intervals for interpretation (1-10: severe impairment; 90-100 superior functioning) (37). As the GAF is scored independently of specific diagnosis and reflects the participant's level of functioning, it supplements conventional symptom- and deficit-oriented diagnoses. The GAF was scored regarding the year before onset 
of $\mathrm{CAD}$, regarding the lowest GAF since onset of CAD and the GAF at the time of the telephone survey.

\section{Procedure}

Participants were contacted by telephone, informed about the content and aim of the telephone survey and asked if they consented to participate. Interviews were conducted by five trained and supervised raters of the psychological and medical staff of the University of Lübeck [one psychologist, one resident physician (psychiatry), one doctoral student (medicine) and two master students (psychology)]. All interviewers were trained in the assessment and regularly supervised by the head of the department (psychiatrist). Then, the time of CAD onset was determined, and the M.I.N.I. was conducted with regard to the participant's mental health before and after the onset of CAD as well as the present. Subsequently, the GAF was scored, and participants were informed about treatment options and contact numbers if necessary and desired by the patient. In case of acute suicidality, the study protocol specified that the psychiatrist on duty should be alerted. This situation did not occur. At the end of the telephone survey, patients were offered a summary of the research findings in layman's terms, to be delivered after completion of the study; if they accepted, their email addresses were collected.

\section{Statistical Analysis}

All statistical analyses were performed using SPSS version 23.0.0.1 for Windows (SPSS Inc., USA). Cramér's V was used as a measure of effect size in $\chi^{2}$ tests. In order to analyze associations between multiple independent variables and one binary dependent variable binary logistic regression analysis were conducted. Critical differences between GAF scores were calculated at a 95\% confidence level with one-sided testing, assuming validity of the equivalence hypothesis. In all other statistical analyses two-sided testing was applied. To dissect interactions in ANOVAs, we employed Hochberg's GT2 post hoc test. Given the exploratory nature of the present study, we refrained from correcting for multiple comparisons in order to prevent accumulation of type II error.

\section{RESULTS}

\section{Demographic and Clinical Characteristics}

Of the initial 1182 patients, 207 patients were known to be already deceased, 138 patients refused to participate, 18 patients could not participate due to cognitive limitations, 26 patients could not participate because communication was not possible (e.g., due insufficient language skills, hearing impairment, or aphasia), 80 patients could not be reached within four attempts, 189 patients could not be reached due to changed contact details, and 13 patients could not be interviewed for other reasons. The final sample consisted of 514 participants (age $M=60.1$ years, $S D=10.11 ; 125$ female, age $M=70.7$ years, $S D=8.31$; 389 male, age $M=63.8$ years, $S D=10.55$ ). There was no difference between the final sample and the dropouts regarding sex ratio $\left(\chi_{(1)}^{2}=1.16, p=0.28\right)$ or obesity $\left(\chi_{(1)}^{2}=2.96\right.$, $p=0.09)$. The median age of the dropout subsample (Md. $=66$ years, IQR $=17)$ was higher than that of the participants of our study $(\mathrm{Md} .=59$ years, $\mathrm{IQR}=15, U=137063.5$, $z=-5.83, p<0.001)$. The median age at CAD onset was 55 years $(\mathrm{IQR}=15)$. Dropouts were more likely to suffer from cardiovascular risk factors at the time of initial admission, e.g., arterial hypertension $\left(\chi_{(1)}^{2}=12.76, p=0.001\right)$, diabetes $\left(\chi_{(1)}^{2}=20.02, p<0.001\right)$ and hypercholesterolemia $\left(\chi_{(1)}^{2}=4.95\right.$, $p=0.03)$; acute or lifetime cardiac infarction $\left(\chi_{(1)}^{2}=10.40\right.$, $p=0.001)$; and limited left ventricular ejection fraction as estimated during echocardiography $\left(\chi_{(1)}^{2}=18.64, p<0.001\right)$.

\section{Prevalence Rates of Mental Disorders}

To assess the prevalence rates of mental disorders over time, we computed descriptive statistics and conducted McNemar's test. The overall lifetime prevalence of mental disorders amounted to $51.4 \%$ (see Table 1), with $37.3 \%$ of participants having suffered from at least one mental disorder before the onset of their CAD and $29.0 \%$ after onset. We found that $16.0 \%$ of participants met the criteria for a mental disorder both before and after onset of CAD (the continuously ill), while $21.3 \%$ met the criteria for a mental disorder only before onset (the remitted) and $12.7 \%$ only after onset of CAD (the newly ill). Finally, 50\% never met the criteria for a mental disorder (the continuously healthy). Higher prevalence rates after the onset of CAD were found for severe depressive episodes (McNemar $\chi^{2}=15.41, p<0.001$ ), dysthymia (exact $p=0.041$ ), panic disorder (exact $p=0.022$ ), agoraphobia $\left(\chi^{2}=17.36, p<0.001\right)$ and hypochondria (exact $p=0.035$ ). For $80.6 \%$ of participants with severe depressive episodes after onset, this was the first manifestation, as for $90.9 \%$ of participants with dysthymia, $88.0 \%$ of participants with panic disorder, $57.6 \%$ of participants with agoraphobia, and $96 \%$ of participants with hypochondria. Lower prevalence rates after the onset of CAD were found for alcohol abuse $\left(\chi^{2}=83.27\right.$, $p<0.001)$ and alcohol dependency $\left(\chi^{2}=18.58, p<0.001\right)$.

\section{Predictors of Poor Mental Health}

To identify predictors of the development of mental disorders after $\mathrm{CAD}$ onset, we performed binary multiple logistic regression analysis including the variables age at onset of $\mathrm{CAD}$, mental health before onset of CAD, GAF in the year before onset of CAD and gender (first block), the duration of CAD defined as the period of time between the onset of CAD and the telephone interview (second block) as well as arterial hypertension, diabetes mellitus, hypercholesterolemia, nicotine consumption, body mass index, and ventricular function (third block) as predictor variables and mental health after onset of $\mathrm{CAD}$ as dependent variable. A model including mental health and GAF before the onset of CAD as well as age at onset of $\mathrm{CAD}$ and gender was a significant fit for the data $\left(\chi_{(4)}^{2}=39.27\right.$, $p<0.001, \mathrm{R}^{2}=0.12$ (Cox \& Snell), $=0.17$ (Nagelkerke); Hosmer-Lemeshow test: $\left.\chi_{(8)}^{2}=7.45, p=0.49\right)$. Participants with any mental disorder before the onset of their CAD and female participants, respectively, were twice as likely to meet the diagnostic criteria for a mental disorder after onset as participants without mental disorder before onset and male participants (Wald $(1)=8.09, p=0.004, \mathrm{OR}=2.18, \mathrm{CI}=[1.27 ; 3.72]$; 


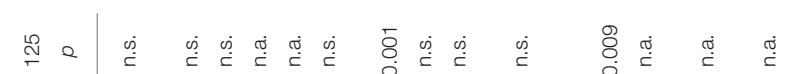

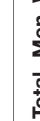

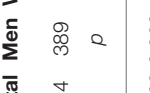

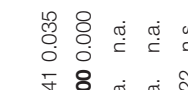

草

它

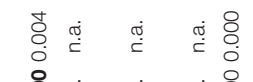

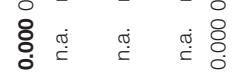

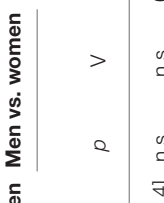

:

宅

$ㅇ ㅡ$

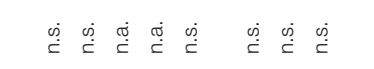

离

高

产

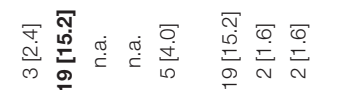

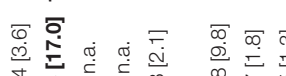

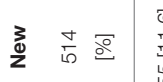

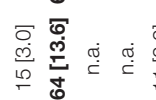

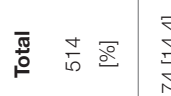

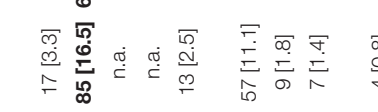

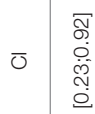

ํ.

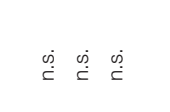

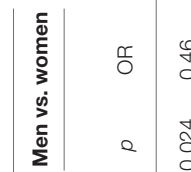

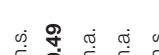

บุ่

is

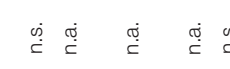

穴

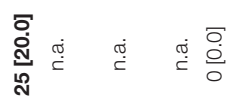

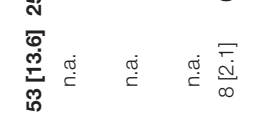

樰

疍

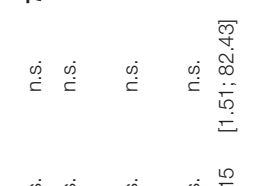

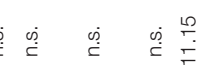

幽

(5)

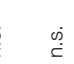

ฝั

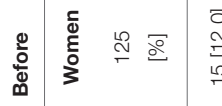

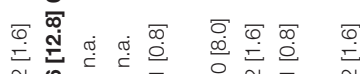

迹

व क नल ल

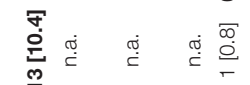

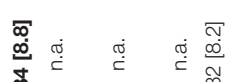

悉

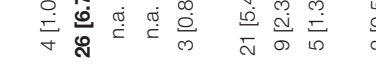

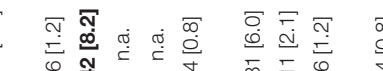

$\overline{0}$

is

ขึ

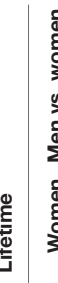

है

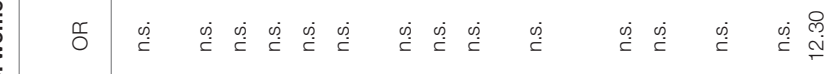

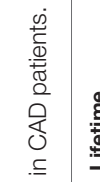

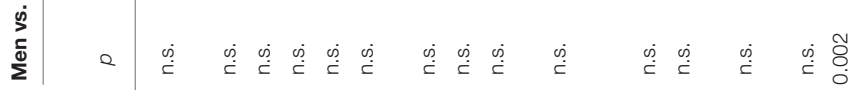

焉

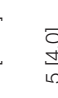

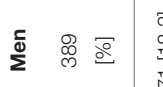

$\overline{0} \overline{0}$

$\frac{F}{\stackrel{\mathrm{N}}{m}}$

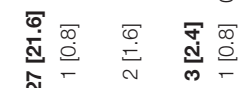

焉

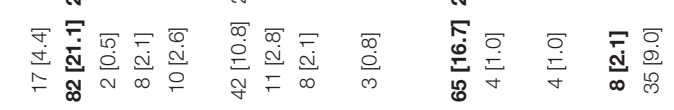

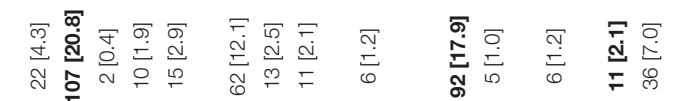

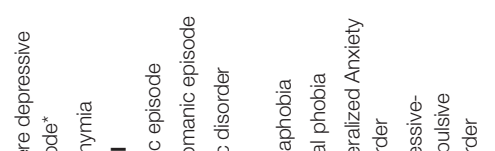

$\stackrel{11}{ᄃ}$

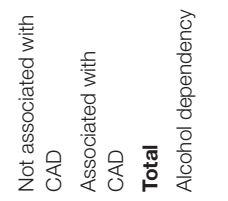

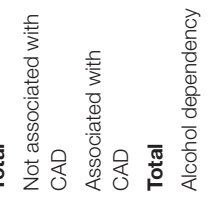

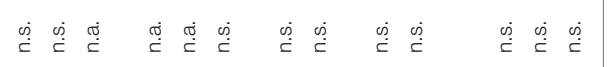

8 O 8 ठ

范

ขอ

ขே

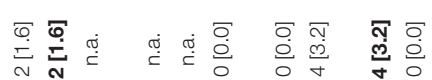

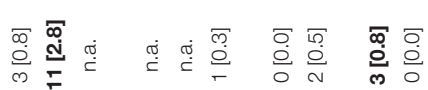

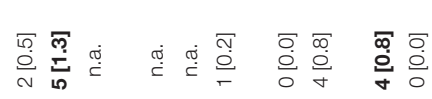

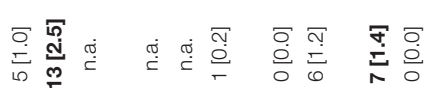

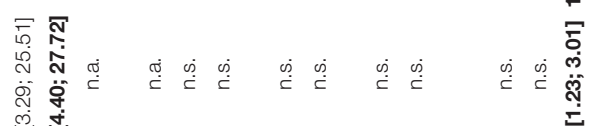

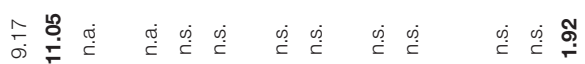

边

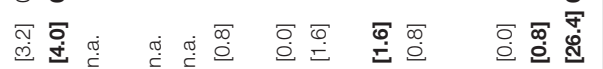

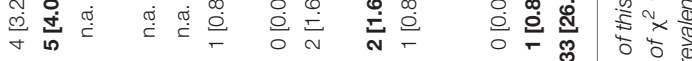

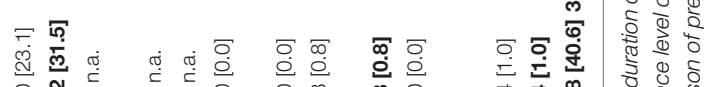

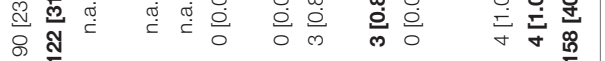

䎹离离

苇

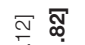

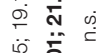

芦

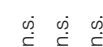

舟

ठठำ

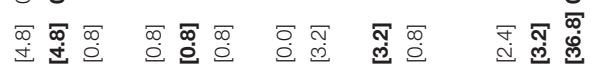

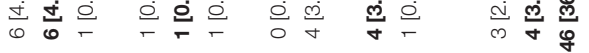

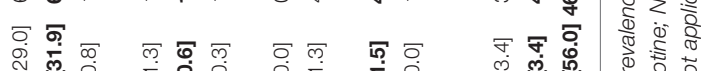

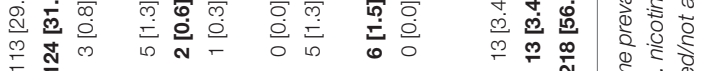

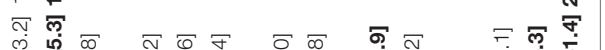

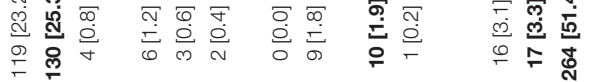

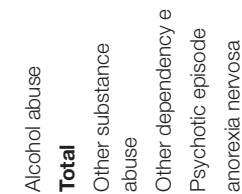

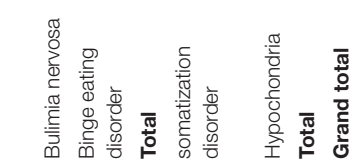

离产竞 ng
昂 
Wald $(1)=4.38, p=0.036, \mathrm{OR}=0.49, \mathrm{CI}=[0.25 ; 0.96])$. Lower GAF before and younger age at onset of CAD were also associated with a higher risk for mental disorders after onset (Wald $(1)=7.91, p=0.005, \mathrm{OR}=0.97, \mathrm{CI}=[0.96 ; 0.99]$ and Wald $(1)=16.79, p<0.001, \mathrm{OR}=0.94, \mathrm{CI}=[0.92 ; 0$ .97]). The duration of CAD; risk factors for atherosclerosis such as obesity and nicotine consumption; elements of the metabolic syndrome such as arterial hypertension, diabetes and hypercholesterolemia; and ventricular function all failed to predict mental health.

To identify predictors of severe depressive episodes after the onset of CAD, we performed binary multiple logistic regression analysis including the variables diagnosis of severe depressive episode before onset of CAD, age at onset of CAD (first block), gender, GAF in the year before onset of CAD, duration of $\mathrm{CAD}$ (second block) and arterial hypertension, diabetes mellitus, hypercholesterolemia, nicotine consumption, body mass index, and ventricular function (third block) as predictor variables and diagnosis of severe depressive episode after onset of CAD as dependent variable. A model including history of severe depressive episodes and age at onset of CAD was a significant fit for the data $\left(\chi_{(2)}^{2}=31.66, p<0.001, \mathrm{R}^{2}=0.10\right.$ (Cox \& Snell), 0.17 (Nagelkerke); Hosmer-Lemeshow test: $\chi_{(8)}^{2}=0.742$, $p=0.99$ ). Patients who had had a severe depressive episode before onset were 11 times as likely as the others to suffer from severe depressive episodes after the onset of their CAD (Wald $(1)=23.38, p<0.001, \mathrm{OR}=11.20, \mathrm{CI}=[4.21 ; 29.83]$ ). Age at onset was negatively associated with severe depressive episodes after the onset of CAD (Wald $(1)=8.87, p=0.003$, $\mathrm{OR}=0.95, \mathrm{CI}=[0.92 ; 0.98])$. Gender; GAF before CAD onset; duration of CAD; risk factors for atherosclerosis such as obesity and nicotine consumption; elements of the metabolic syndrome such as arterial hypertension, diabetes and hypercholesterolemia; and ventricular function failed to predict severe depressive episodes after the onset of CAD.

For predicting agoraphobia after the onset of CAD, we performed binary multiple logistic regression analysis including the variables diagnosis of agoraphobia before onset of CAD, gender, age at onset of CAD, GAF in the year before onset of CAD (first block), duration of CAD (second block) and arterial hypertension, diabetes mellitus, hypercholesterolemia, nicotine consumption, body mass index, and ventricular function (third block) as predictor variables and diagnosis of agoraphobia after onset of CAD as dependent variable. A model including history of agoraphobia, GAF before onset of CAD, gender, and age at onset of CAD was a significant fit for the data $\left(\chi_{(4)}^{2}=62.67, p<0.001\right.$, $\mathrm{R}^{2}=0.18$ (Cox \& Snell), 0.37 (Nagelkerke); Hosmer-Lemeshow test: $\left.\chi_{(8)}^{2}=7.70, p=0.46\right)$. Patients with agoraphobia before onset were 44 times as likely as those without to suffer from agoraphobia after the onset of their CAD (Wald $(1)=34.10$, $p<0.001, \mathrm{OR}=44.01, \mathrm{CI}=[12.36 ; 156.74])$. Women were four times as likely as men to suffer from agoraphobia after the onset of CAD (Wald $(1)=6.80, p=0.009$, OR $=0.26$, $\mathrm{CI}=[0.09 ; 0.72])$. GAF before and age at onset of CAD were negatively associated with agoraphobia after onset (Wald $(1)=3.90, p=0.048, \mathrm{OR}=0.98, \mathrm{CI}=[0.95 ; 1.00]$; Wald
(1) $=5.26, p=0.022, \mathrm{OR}=0.95, \mathrm{CI}=[0.91 ; 0.99])$. The duration of CAD; risk factors for atherosclerosis such as obesity and nicotine consumption; elements of the metabolic syndrome such as arterial hypertension, diabetes, and hypercholesterolemia; and ventricular function failed to predict agoraphobia after the onset of CAD.

\section{Gender Differences Regarding Prevalence Rates of Mental Disorders}

To examine gender differences in prevalence rates of mental disorders, we calculated $\chi^{2}$ (see Table 1). There was a gender difference in alcohol-related disorders before the onset of CAD, including both abuse $\left(\chi_{(1)}^{2}=23.36, p<0.001\right.$, OR $=9.17$, $\mathrm{CI}=[3.29 ; 25.51])$ and dependency $\left(\chi_{(1)}^{2}=8.71, p=0.003\right.$, $\mathrm{OR}=11.15, \mathrm{CI}=[1.51 ; 82.43])$, resulting in differences in lifetime prevalence $\left(\chi_{(1)}^{2}=31.53, p<0.001, \mathrm{OR}=8.18\right.$, $\mathrm{CI}=[3.5 ; 19.12] ; \chi_{(1)}^{2}=9.79, p=0.002, \mathrm{OR}=12.30, \mathrm{CI}=[167$; 90.69]). Regarding the period before the onset of their CAD, men were nine times as likely as women to meet the criteria for alcohol abuse and 11 times as likely to meet the criteria for alcohol dependency. In the period after the onset of CAD, the prevalence rates of alcohol-related disorders dropped to a level similar to that found in women.

Regarding severe depressive episodes before the onset of CAD, there was a gender difference $\left(\chi_{(1)}^{2}=5.08, p=0.02, \mathrm{OR}=0.46\right.$, $\mathrm{CI}=[0.23 ; 0.92])$. Women were twice as likely as men to meet the criteria for severe depressive episodes in the years before their $\mathrm{CAD}$ manifested. However, in the years after onset, prevalence in men increased to the level found in women. Therefore, there was no gender difference in point or lifetime prevalence of severe depressive episodes.

There was a gender difference in the prevalence of binge eating disorder after the onset of CAD $\left(\chi_{(1)}^{2}=5.92\right.$, exact $p=0.033$, $\mathrm{OR}=0.16, \mathrm{CI}=[0.03 ; 0.86])$. Women were five times as likely as men to meet the criteria for binge eating disorder. The prevalence rates for the period before CAD onset showed the same trend, although not to a significant level, with women being twice as likely to suffer from binge eating disorder as men; lifetime prevalence followed a similar pattern.

Regarding prevalence of obsessive-compulsive disorder, there was a gender difference after the onset of CAD $\left(\chi_{(1)}^{2}=5.63\right.$, exact $p=0.046, \mathrm{OR}=0.11, \mathrm{CI}=[0.01 ; 1.12])$. Women were 10 times more likely than men to meet the criteria for obsessive-compulsive disorder. The prevalence rates for obsessive-compulsive disorder at the other time points/periods showed the same trend, although not to a significant level, with women being two to five times as likely to suffer from obsessive compulsive disorder as men.

\section{Psychosocial Functioning}

To examine the course of GAF over time, we conducted a threeway mixed ANOVA with repeated measures, with time as a within-subjects factor (year before onset of CAD/lowest GAF after onset/at the time of the interview), gender and mental 
health (continuously healthy/remitted/continually ill/newly ill) as between-subjects factors (see also Figure 1).

There was a main effect of time (Greenhouse-Geissercorrected $\left.\mathrm{F}_{(1.77,894.09)}=167.12, p<0.001, \eta_{\mathrm{p}}^{2}=0.25\right)$. The mean GAF was $82.04(S D=17.70)$ in the year before CAD onset and decreased to a minimum of $66.51 \mathrm{GAF}$ points $(S D=20.32)$ after CAD onset [SD of $\Delta=21.43, \mathrm{~F}_{(1,504)}=268.84, p<0.001$, $\eta_{\mathrm{p}}^{2}=0.35$ ]. We found that 337 participants $(65.7 \%)$ experienced significant loss of GAF, while 27 (5.3\%) improved. From the onset of $\mathrm{CAD}$ until the interview, participants regained an average of 7.34 GAF points $(S D=15.61)$, but GAF was still decreased in comparison to the year before CAD onset $\left[\mathrm{F}_{(1,504)}=114.25\right.$, $\left.p<0.001, \eta_{p}^{2}=0.19\right]$. We found that 259 participants $(50.5 \%)$ experienced significant loss of GAF between the year before onset of CAD and the interview, while 68 participants (13.3\%) improved.

There was a main effect of mental health $\left[\mathrm{F}_{(3,502)}=40.91\right.$, $\left.p<0.001, \eta_{\mathrm{p}}^{2}=0.20\right]$. Continuously ill participants scored 5.86 GAF points lower than newly ill participants $(S D=24.48$, $p=0.023)$, who in turn scored lower than remitted participants $(\Delta=8.63 \mathrm{GAF}$ points, $S D=30.56, p<0.001)$ as well as continuously healthy participants $(\Delta=8.99$ GAF points, $S D=30.92, p=0.001)$. There was no difference between remitted and continuously healthy participants $(\Delta=0.35$ GAF points, $S D=34.92)$.

There was no main effect of gender $(\Delta=1.84$ GAF points, $S D=30.77)$, but there was a gender $\mathrm{x}$ mental health interaction $\left(\mathrm{F}_{(3,504)}=3.23, p=0.022, \eta_{\mathrm{p}}^{2}=0.02\right)$. GAF in newly ill men was similar to GAF in continuously ill men $(M=66.82, S D=11.49$ and $\mathrm{M}=65.58, S D=9.78)$ and lower than the GAF in remitted $(M=79.32, S D=10.02)$ and continuously healthy men $(\mathrm{M}=81.14, S D=10.60)$. GAF in newly ill women was on average 75.56 GAF points $(S D=9.29)$, which was higher than that of continuously ill women $(\mathrm{M}=65.09, S D=11.10)$ but did not differ from GAF in remitted $(M=80.33, S D=9.90)$ or continuously healthy women $(\mathrm{M}=79.22, S D=8.74)$.

\section{DISCUSSION}

In our sample, one in three participants met the criteria for a mental disorder after the onset of their CAD, with women, young participants and participants with a mental disorder or poor psychosocial functioning before the onset of CAD especially at risk. However, even of the participants with good mental health before the onset of CAD, one in five developed a mental disorder in the years after onset of CAD. Severe depressive episodes and dysthymia as well as agoraphobia, panic disorder and hypochondria were more than twice as prevalent after the onset of CAD, although this period was seven times shorter. Sixty to ninety percent of these affective and anxiety disorders were first manifestations. Men were half as likely as women to suffer from depression before the onset of CAD, but after onset, the probabilities equalized. Psychosocial functioning decreased after the onset of CAD and recovered only partially, even in participants who never met the criteria for a severe mental disorder. In women but not men, psychosocial functioning after the onset of CAD was influenced by mental health before the onset.

Interestingly, the prevalence of severe depressive episodes after CAD onset (14.4\%, median duration of this period was 8 years) was higher than in the elderly German general population [12-month prevalence: $11.3 \%$ in women and $4.8 \%$ in men (38)] but lower than in previous studies on CAD patients $(7,8)$, which may be due to the fact, that our study only included more severe depressive episodes, due to overestimation in other studies because of their use of self-report measures or due to the fact that most studies assessed patients during hospitalization after an acute cardiologic event. Regarding the period before the onset of CAD, we found the well-established gender difference of 2:1 (women:men) in the prevalence rates of severe depressive episodes. After the onset of CAD, however, the prevalence in men rose to the level found in women. This is in conflict with a meta-analysis on CAD patients finding an odds ratio of 1.8:1 (women:men) (39). However, the authors themselves rated the quality of evidence as low, mainly because of lack of adjustment for confounding factors. Another reason for the difference in gender distribution in this sample could be the fact that we only included more severe depressive episodes.

The most prevalent anxiety disorder in our sample was agoraphobia, which was three to five times more frequent in our sample than in the German general population, whereas the prevalence rates of other anxiety disorder were similar (40). This is in accordance with the study by Sardinha, Araújo (12), who found agoraphobia to be highly prevalent as well as the most prevalent anxiety disorder in Brazilian CAD patients. Other studies, however, have identified GAD as the prevailing anxiety disorder in CAD patients (10-12\%), with other anxiety disorders including agoraphobia being less prevalent (agoraphobia 2$4 \%$, social phobia $3-9 \%$, panic disorder $2-8 \%(9,10)]$. This discrepancy is probably not explained by phenomenological differences between study populations. More likely it is explained by the attribution of symptoms such as anxiety and avoidance to different diagnostic categories. This difference could be attributable to the use of different (versions of) psychometric instruments or intercultural differences in concepts of mental health. For example, patients in our German sample may have judged an increase in worrying as normal after a cardiac event and thus denied being overly worried. Additionally, CAD-related anxiety may not be adequately represented by any currently employed category of anxiety disorder and thus may need to be conceptualized independently in future research.

The low prevalence of post-traumatic stress disorder in our sample is consistent with data from the German general population (41). Interestingly, in the majority of participants suffering from post-traumatic stress disorder, the A1 criterion was closely associated with CAD and related medical procedures. This finding adds to the small but growing body of research on medically related post-traumatic stress disorder $(42,43)$ and highlights the need for research into modifiable risk factors for medically related post-traumatic stress disorder as well as routine screening of CAD patients for mental disorders followed by mental health treatment as necessary. 

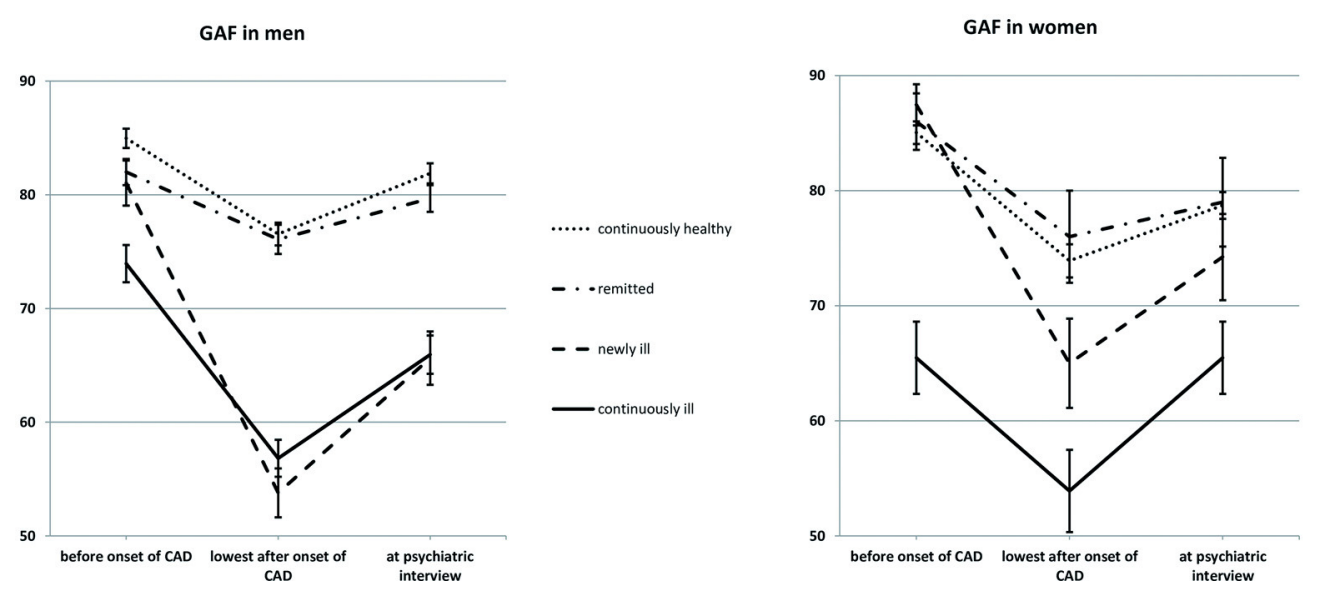

FIGURE 1 | Psychosocial functioning as a function of gender and mental health. Sample size: 387 men and 125 women. Mean GAF scores are given; errors bars indicate standard errors. GAF, Global Assessment of Functioning; CAD, coronary artery disease; Continuously healthy, never met the criteria for a mental disorder before or after the onset of CAD (50.0\%); Remitted, met the criteria for a mental disorder before but not after the onset of CAD (21.3\%); Newly ill, met the criteria for a mental disorder after, but not before the onset of CAD (12.7\%); Continuously ill, met the criteria for a mental disorder both before and after the onset of CAD (16.0\%).

After the onset of CAD, binge eating disorder was twice as frequent in our sample as in the general population (44), which is in accordance with one other study published to date (12). This increased frequency of binge eating disorder could reflect selection bias as a common complication of binge eating disorder is obesity, which in turn is a risk factor for CAD, the main inclusion criterion for this study. On the other hand, CADrelated loss of mobility could leave patients with eating as one of only a few remaining emotion regulation strategies. Future research should explore this relationship between CAD and binge eating disorder in more detail, taking possible mediators such as depression into account. The gender differences in binge eating disorder found in the present study, although significant, must be interpreted with caution given the low number of cases and the type I error inflation due to multiple testing.

The finding that the prevalence of hypochondria was higher after onset, while the prevalence of somatization disorder was not, likely reflects methodological issues rather than phenomenological differences, as the DSM-IV diagnostic criteria for somatization disorder require manifestation before the age of 30 . As the median onset of CAD was 55 years, CAD could not influence the development of somatization disorder. As somatization disorder has recently been reconceptualized into somatic symptom disorder and no longer holds an age criterion for first manifestation (45), this question should be addressed again in future studies.

The higher rate of mental disorders and the low psychosocial functioning after CAD onset may be due to the loss of positive reinforcements as CAD is often accompanied by functional and physical limitations which can lead to a reduction of value-based behavior (e.g., work, hobbies, sport, social activities). Another reason could be neurocognitive deterioration as a result of cerebrovascular disease, which is known to be associated with cardiovascular disease $(46,47)$.
Regarding risk factors for mental disorders after the onset of CAD, somatic variables were not relevant. This could be due to type II error caused by high somatic comorbidity and lack of variance in our sample, as vascular risk factors are known to be risk factors for depressive episodes (48).

The strengths of the present study are the high methodological quality of assessment of distinct mental disorders, as opposed to self-rating of mere psychological symptoms, and the consideration of all major mental disorders as opposed to only a few psychological symptoms. Furthermore, we adjusted for the confounding factor of previous mental health and supplemented diagnostic assessment with a measure of psychosocial functioning, allowing for inferences on the practical relevance of the results. The timing of assessment well after hospitalization allowed for differentiation between adaptive emotional reaction to an existential threat and psychopathology, but it also could have led to underestimation of prevalence due to selection bias caused by excess mortality in cardiac patients with severe mental disorders $(49,50)$. Another limitation of this study is its retrospective design, which may have led to underestimation of prevalence rates before the onset of CAD due to memory bias. A longitudinal study would be desirable. Also, milder forms of mental disorders, such as milder forms of depressive episodes and adjustment disorders were not included in this study. The risk of poor outcome in patients with CAD does seem to increase with higher severity of depressive symptomatology (19), however, even subclinical depressive symptoms have been identified to be associated with poor outcome in patients with CAD (51). This should be considered in future research on mental disorders in patients with $\mathrm{CAD}$ and common forms of milder mental disorders such as adjustment disorders and all kind of depressive episodes should be included. Another limitation is the lack of adjustment for socioeconomic characteristics such as socioeconomic status and marital status, which are known to influence mental 
health (52). The assessment of psychosocial functioning by using the GAF-score is another possible limitation of this study as data on psychometric properties of the GAF are inconsistent and more recent studies indicated weaknesses (e.g., regarding the inter-rater reliability) $(53,54)$. In future research alternative instruments for the assessment of psychosocial functioning such as the WHO Disability Assessment Schedule 2.0 (WHODAS 2.0) (55) should be considered. Additionally, assessment by telephone may have confounded the results due to (a) increased risk of misunderstanding because of lack of nonverbal communication and (b) selection bias as severely mentally ill patients are less likely to answer the phone. Thus, our study may underestimate the prevalence of mental disorders.

\section{CONCLUSION}

Mental disorders-especially depressive and anxiety disordersare frequent in patients with CAD, with women, young patients and patients with any history of mental disorder especially at risk. Regardless of whether patients meet any specific diagnostic criteria, psychosocial functioning is markedly impaired after the onset of CAD, underscoring the need for specific mental health programs for this patient population. Future research is necessary to explore the phenomenology of anxiety and assess somatization in CAD patients as well as search for modifiable risk factors for mental disorders in patients with somatic illnesses. Health care for CAD patients should include routine screening at

\section{REFERENCES}

1. Benjamin EJ, Blaha MJ, Chiuve SE, Cushman M, Das SR, Deo R, et al. Heart disease and stroke statistics-2017 update: a report from the American Heart Association Circulation (2017) 135:e146-603. doi: 10.1161/CIR.0000000000000485

2. World Health Organization. World Health Statistics 2016: Monitoring Health for the SDGs Sustainable Development Goals: World Health Organization (2016).

3. Busch M, Kuhnert R. Prävalenz einer koronaren Herzkrank-heit in Deutschland. J Health Monitor. (2017) 2:64-9.

4. Robert Koch-Institut. Daten und Fakten: Ergebnisse der Studie $\gg$ Gesundheit in Deutschland aktuell 2010. Beiträge zur Gesundheitsberichterstattung des Bundes. Berlin: Robert Koch-Institut (2012).

5. Mozaffarian D, Benjamin EJ, Go AS, Arnett DK, Blaha MJ, Cushman $\mathrm{M}$, et al. Executive summary: heart disease and stroke statistics2016 update: a report from the American Heart Association. Circulation (2016) 133:447-54. doi: 10.1161/CIR.0000000000 000366

6. Rosamond W, Flegal K, Furie K, Go A, Greenlund K, Haase $\mathrm{N}$, et al. Heart disease and stroke statistics--2008 update. Circulation (2008) 117:e25-146. doi: 10.1161/CIRCULATIONAHA.107. 187998

7. Pajak A, Jankowski P, Kotseva K, Heidrich J, De Smedt D, De Bacquer D. Depression, anxiety, and risk factor control in patients after hospitalization for coronary heart disease: the EUROASPIRE III Study. Eur J Prevent Cardiol. (2013) 20:331-40. doi: 10.1177/2047487312 441724

8. Celano CM, Huffman JC. Depression and cardiac disease: a review. Cardiol Rev. (2011) 19:130-42. doi: 10.1097/CRD.0b013e3182 $0 \mathrm{e} 8106$ regular intervals for mental disorders, followed by mental health treatment as necessary.

\section{ETHICS STATEMENT}

The study was approved by the ethics committee of Lübeck University, Germany (reference number: 04/041). Informed consent was obtained from all participants prior to inclusion in the study.

\section{AUTHOR CONTRIBUTIONS}

BW, CW, HS, JE, and US contributed conception and design of the study. AS, AW, BW, and SN acquired the data and organized the database. AS, AW, and US performed the statistical analysis. AS and AW wrote the first draft of the manuscript. AS, AW, $\mathrm{SN}, \mathrm{MM}, \mathrm{BW}, \mathrm{CW}, \mathrm{HS}$, JE, and US contributed to manuscript revision.

\section{FUNDING}

The study was funded by the Lübeck University.

\section{ACKNOWLEDGMENTS}

We thank all patients and the student research assistants Sandra Köhne and Marie Luise Bußmann for their participation in this study.

9. Parker GB, Owen CA, Brotchie HL, Hyett MP. The impact of differing anxiety disorders on outcome following an acute coronary syndrome: time to start worrying? Depress Anxiety (2010) 27:302-9. doi: 10.1002/da. 20602

10. Tully PJ, Penninx BW. Depression and anxiety among coronary heart disease patients: can affect dimensions and theory inform diagnostic disorder-based screening? J Clin Psychol. (2012) 68:448-61. doi: 10.1002/jc lp. 21828

11. Bankier B, Januzzi JL, Littman AB. The high prevalence of multiple psychiatric disorders in stable outpatients with coronary heart disease. Psychosom Med. (2004) 66:645-50. doi: 10.1097/01.psy.0000138126.90551.62

12. Sardinha A, Araújo C, Nardi A. Psychiatric disorders and cardiac anxiety in exercising and sedentary coronary artery disease patients: a case-control study. Braz J Med. Biol Res. (2012) 45:1320-6. doi: 10.1590/S0100-879X2012007500156

13. Swardfager W, Herrmann N, Marzolini S, Saleem M, Farber SB, Kiss A, et al. Major depressive disorder predicts completion, adherence, and outcomes in cardiac rehabilitation: a prospective cohort study of 195 patients with coronary artery disease. J Clin Psychiatry (2011) 72:1181-8. doi: 10.4088/JCP.09m05810blu

14. Dempe C, Jünger J, Hoppe S, Katzenberger ML, Möltner A, Ladwig KH, et al. Association of anxious and depressive symptoms with medication nonadherence in patients with stable coronary artery disease. J Psychosom Res. (2013) 74:122-7. doi: 10.1016/j.jpsychores.2012.12.003

15. Gehi A, Haas D, Pipkin S, Whooley MA. Depression and medication adherence in outpatients with coronary heart disease: findings from the Heart and Soul Study. Arch Int Med. (2005) 165:2508-13. doi: 10.1001/archinte.165.21.2508

16. Ziegelstein RC, Fauerbach JA, Stevens SS, Romanelli J, Richter DP, Bush DE. Patients with depression are less likely to follow recommendations to reduce cardiac risk during recovery from a myocardial 
infarction. Arch Int Med. (2000) 160:1818-23. doi: 10.1001/archinte.160. 12.1818

17. Van Dijk MR, Utens EM, Dulfer K, Al-Qezweny MN, van Geuns R-J, Daemen $\mathrm{J}$, et al. Depression and anxiety symptoms as predictors of mortality in PCI patients at 10 years of follow-up. Eur J Prev Cardiol. (2016) 23:552-8. doi: 10.1177/2047487315571889

18. Szpakowski N, Bennell MC, Qiu F, Ko DT, Tu JV, Kurdyak P, et al. Clinical impact of subsequent depression in patients with a new diagnosis of stable angina. Circ Cardiovasc Qual Outcomes (2016) 9:731-9. doi: 10.1161/CIRCOUTCOMES.116.002904

19. Penninx BW, Beekman AT, Honig A, Deeg DJ, Schoevers RA, van Eijk JT, et al. Depression and cardiac mortality: results from a communitybased longitudinal study. Arch Gen Psychiatry (2001) 58:221-7. doi: 10.1001/archpsyc.58.3.221

20. Lichtman JH, Froelicher ES, Blumenthal JA, Carney RM, Doering LV, FrasureSmith N, et al. Depression as a risk factor for poor prognosis among patients with acute coronary syndrome: systematic review and recommendations: a scientific statement from the American Heart Association. Circulation (2014) 129:1350-69. doi: 10.1161/CIR.0000000000000019

21. Roest AM, Martens EJ, de Jonge P, Denollet J. Anxiety and risk of incident coronary heart disease: a meta-analysis. J Am Coll Cardiol. (2010) 56:38-46. doi: 10.1016/j.jacc.2010.03.034

22. Watkins LL, Koch GG, Sherwood A, Blumenthal JA, Davidson JR, O'Connor $\mathrm{C}$, et al. Association of anxiety and depression with all-cause mortality in individuals with coronary heart disease. J Am Heart Assoc. (2013) 2:e000068. doi: 10.1161/JAHA.112.000068

23. Baumeister H, Haschke A, Munzinger M, Hutter N, Tully PJ. Inpatient and outpatient costs in patients with coronary artery disease and mental disorders: a systematic review. Biopsychosoc Med. (2015) 9:11. doi: 10.1186/s13030-015-0039-z

24. Palacios JE, Khondoker M, Achilla E, Tylee A, Hotopf M. A single, oneoff measure of depression and anxiety predicts future symptoms, higher healthcare costs, and lower quality of life in coronary heart disease patients: analysis from a multi-wave, primary care cohort study. PloS ONE (2016) 11:e0158163. doi: 10.1371/journal.pone.0158163

25. Rutledge T, Redwine LS, Linke SE, Mills PJ. A meta-analysis of mental health treatments and cardiac rehabilitation for improving clinical outcomes and depression among patients with coronary heart disease. Psychosom Med. (2013) 75:335-49. doi: 10.1097/PSY.0b013e318 291d798

26. Whalley B, Thompson DR, Taylor RS. Psychological interventions for coronary heart disease: cochrane systematic review and metaanalysis. Int J Behav Med. (2014) 21:109-21. doi: 10.1007/s12529-0129282-x

27. Richards SH, Anderson L, Jenkinson CE, Whalley B, Rees K, Davies P, et al. Psychological interventions for coronary heart disease. Cochrane Lib. (2017) 4:CD002902. doi: 10.1002/14651858.CD002902.pub4

28. Hergueta T, Baker R, Dunbar GC. The Mini-International Neuropsychiatric Interview (MINI): the development and validation of a structured diagnostic psychiatric interview for DSM-IVand ICD-10. J Clin Psychiatry (1998) 59(Suppl 20):2233.

29. Ackenheil M, Stotz-Ingenlath G, Dietz-Bauer R, Vossen A. MINI Mini International 522 Neuropsychiatric Interview, German version 5.0. 0 DSM IV. Munich: Psychiatric University Clinic 523 (1999).

30. TSaß H, Wittchen H-U, Zaudig M. Diagnostisches und Statistisches Manual Psychischer Störungen-DSM-IV. Deutsche Bearbeitung u. Göttingen: Hogrefe (1996).

31. World Health Organization. ICD-10: Internationale statistische Klassifikation der Krankheiten und verwandter Gesundheitsprobleme, 10. Revision: Huber (1996).

32. Lecrubier Y, Sheehan DV, Weiller E, Amorim P, Bonora I, Sheehan KH, et al., The Mini International Neuropsychiatric Interview (MINI). A short diagnostic structured interview: reliability and validity according to the CIDI. Eur Psychiatry (1997) 12:224-31. doi: 10.1016/S0924-9338(97)83296-8

33. Klein JP, Berger T, Schröder J, Späth C, Meyer B, Caspar F, et al. The EVIDENT-trial: protocol and rationale of a multicenter randomized controlled trial testing the effectiveness of an online-based psychological intervention. BMC Psychiatry (2013) 13:239. doi: 10.1186/1471-244X13-239

34. Stecker T, Fortney J, Hamilton F, Sherbourne CD, Ajzen I. Engagement in mental health treatment among veterans returning from Iraq. Patient Pref Adher. (2010) 4:45. doi: 10.2147/PPA.S7368

35. Watts S, Mackenzie A, Thomas C, Griskaitis A, Mewton L, Williams A, et al. CBT for depression: a pilot RCT comparing mobile phone vs. computer. BMC Psychiatry (2013) 13:49. doi: 10.1186/1471-244X-13-49

36. Hilsenroth MJ, Ackerman SJ, Blagys MD, Baumann BD, Baity MR, Smith SR, et al. Reliability and validity of DSM-IV axis V., Am J Psychiatry (2000) 157:1858-63. doi: 10.1176/appi.ajp.157.11.1858

37. American Psychiatric Association. DSM-IV-TR: Diagnostic and Statistical Manual of Mental Disorders, Text Revision. Washington, DC: American Psychiatric Association (2000).

38. Wittchen H-U, Jacobi F, Klose M, Ryl L. Gesundheitsberichterstattung des Bundes, Heft 51. Berlin: Robert Koch-Institut (2010).

39. Shanmugasegaram S, Russell KL, Kovacs AH, Stewart DE, Grace SL. Gender and sex differences in prevalence of major depression in coronary artery disease patients: a meta-analysis. Maturitas (2012) 73:305-11. doi: 10.1016/j.maturitas.2012.09.005

40. Wittchen H-U, Jacobi F, Klose M, Ryl L. Gesundheitsberichterstattung des Bundes Heft 21. Berlin: Robert Koch-Institut (2010).

41. Lukaschek K, Kruse J, Emeny RT, Lacruz ME, von Eisenhart Rothe A, Ladwig K-H. Lifetime traumatic experiences and their impact on PTSD: a general population study. Soc Psychiatry Psychiat Epidemiol. (2013) 48:525-32. doi: 10.1007/s00127-012-0585-7

42. Chung MC, Berger Z, Rudd H. Coping with posttraumatic stress disorder and comorbidity after myocardial infarction., Compreh Psychiat. (2008) 49:55-64. doi: 10.1016/j.comppsych.2007.08.003

43. Wintermann G-B, Weidner K, Strauß B, Rosendahl J, Petrowski K. Predictors of posttraumatic stress and quality of life in family members of chronically critically ill patients after intensive care. Annals of Intensive Care (2016) 6:69. doi: 10.1186/s13613-016-0174-0

44. Preti A, de Girolamo G, Vilagut G, Alonso J, de Graaf R, Bruffaerts R, et al. The epidemiology of eating disorders in six European countries: results of the ESEMeD-WMH project. J Psychiat Res. (2009) 43:1125-32. doi: 10.1016/j.jpsychires.2009.04.003

45. American Psychiatric Association. Diagnostic and Statistical Manual of Mental Disorders (DSM-5®): American Psychiatric Pub (2013).

46. Subherwal S, Bhatt DL, Li S, Wang TY, Thomas L, Alexander KP, et al. Polyvascular disease and long-term cardiovascular outcomes in older patients with Non-ST-segment-elevation myocardial infarction. circulation: cardiovascular quality and outcomes (2012) 5:541-9. doi: 10.1161/CIRCOUTCOMES.111.964379

47. Vagnarelli F, Corsini A, Lorenzini M, Ortolani P, Norscini G, Cinti L, et al. Long-term prognostic role of cerebrovascular disease and peripheral arterial disease across the spectrum of acute coronary syndromes. Atherosclerosis (2016) 245:43-9. doi: 10.1016/j.atherosclerosis.2015. 11.014

48. Valkanova V, Ebmeier KP. Vascular risk factors and depression in later life: a systematic review and meta-analysis. Biol Psychiatry (2013) 73:406-13. doi: 10.1016/j.biopsych.2012.10.028

49. Bodén R, Molin E, Jernberg T, Kieler H, Lindahl B, Sundström J. Higher mortality after myocardial infarction in patients with severe mental illness: a nationwide cohort study. J Int Med. (2015) 277:727-36. doi: 10.1111/joim.12329

50. Smolderen KG, Buchanan DM, Gosch K, Whooley MA, Chan PS, Vaccarino V, et al. Depression treatment and 1-year mortality following acute myocardial infarction: insights from the TRIUMPH Registry. Circulation (2017) 135:1681-9. doi: 10.1161/CIRCULATIONAHA.116. 025140

51. Bush DE, Ziegelstein RC, Tayback M, Richter D, Stevens S, Zahalsky $\mathrm{H}$, et al. Even minimal symptoms of depression increase mortality risk after acute myocardial infarction. Am J Cardiol. (2001) 88:337-41. doi: 10.1016/S0002-9149(01)01675-7

52. Friedli L. Mental Health, Resilience and Inequalities. World Health Organization (2009). 
53. Grootenboer E, Giltay EJ, van der Lem R, van Veen T, van der Wee NJ, Zitman FG. Reliability and validity of the global assessment of functioning scale in clinical outpatients with depressive disorders. J Evaluat Clin Pract. (2012) 18:502-7. doi: 10.1111/j.1365-2753.2010.01614.x

54. Vatnaland T, Vatnaland J, Friis S, Opjordsmoen S. Are GAF scores reliable in routine clinical use? Acta Psychiatrica Scandinavica (2007) 115:326-30. doi: $10.1111 / j .1600-0447.2006 .00925 . x$

55. Üstün TB, Chatterji S, Kostanjsek N, Rehm J, Kennedy C, Epping-Jordan J, et al. Developing the world health organization disability assessment schedule 2.0. Bull World Health Organ. (2010) 88:815-23. doi: 10.2471/BLT.09. 067231
Conflict of Interest Statement: The authors declare that the research was conducted in the absence of any commercial or financial relationships that could be construed as a potential conflict of interest.

Copyright (๑) 2018 Schaich, Westermair, Munz, Nitsche, Willenborg, Willenborg, Schunkert, Erdmann and Schweiger. This is an open-access article distributed under the terms of the Creative Commons Attribution License (CC BY). The use, distribution or reproduction in other forums is permitted, provided the original author(s) and the copyright owner(s) are credited and that the original publication in this journal is cited, in accordance with accepted academic practice. No use, distribution or reproduction is permitted which does not comply with these terms. 